\title{
Dietitians use and recommend dietary supplements: report of a survey
}

Annette Dickinson ${ }^{1 *}$, Leslie Bonci ${ }^{2}$, Nicolas Boyon ${ }^{3}$ and Julio C Franco ${ }^{3}$

\begin{abstract}
Background: Dietary supplement use is common in the United States, with more than half of the population using such products. Nutrition authorities consistently advocate a "food first" approach to achieving nutritional adequacy but some, including the Academy of Nutrition and Dietetics (formerly the American Dietetic Association), also recognize that dietary supplements have a role to play in improving nutrient intake to support health and wellness. Surveys show that many health professionals use dietary supplements themselves and also recommend dietary supplements to their patients or clients.
\end{abstract}

Methods: As one component of a series of surveys of healthcare professionals (the "Life...supplemented" HCP Impact Studies), 300 registered dietitians were surveyed in 2009 regarding their personal use of dietary supplements and whether they recommend dietary supplements to their clients. Respondents were registered dietitians whose business involved seeing clients in a private practice or at a clinic.

Results: Seventy-four percent of the dietitians surveyed said they were regular users of dietary supplements, while $22 \%$ said they used dietary supplements occasionally or seasonally. The primary reasons for using dietary supplements were for bone health (58\%), overall health and wellness (53\%), and to fill nutrient gaps (42\%). When asked if they "ever recommend dietary supplements to clients," 97\% of the respondents said they did. The primary reasons were for bone health (70\%), to fill nutrient gaps (67\%), and overall health and wellness (49\%). Eighty-seven percent of the dietitians agreed with the statement, "There are gaps in clients' diets that could effectively be addressed with dietary supplements." The dietitians surveyed said they followed healthy habits including eating a balanced diet (96\%), managing stress (92\%), visiting their own healthcare professional regularly (86\%), exercising regularly (83\%), maintaining a healthy weight (80\%), and getting a good night's sleep (72\%). Nearly all respondents (95\%) expressed an interest in continuing education about dietary supplements on a variety of topics.

Conclusions: Many dietitians, like other health professionals, use dietary supplements regularly as part of their own approach to a healthy diet and lifestyle. They also recommend dietary supplements to their clients or patients, to promote health.

Keywords: Dietary supplements, Supplement surveys, Dietitians' health habits

\section{Background}

Dietary supplement use is common among U.S. adults, according to the National Health and Nutrition Examination Surveys (NHANES), with the prevalence of dietary supplement use in the month preceding the survey reported to be $52 \%$ in the $1999-2000$ NHANES and $54 \%$ in the 2003-2006 NHANES [1,2]. These surveys show

\footnotetext{
* Correspondence: annettedickinson@comcast.net

'Dickinson Consulting, LLC, 3432 Denmark Avenue, \#350, St. Paul, MN 55123, USA

Full list of author information is available at the end of the article
}

that usage is higher among older adults than among young adults, higher among women than among men, and increases as the level of education increases. Most users of dietary supplements say their primary motivation is to improve overall health or wellness or to fill perceived nutrient gaps in their dietary intake [3].

National nutrition surveys show that many Americans fall short in consumption of several vitamins and minerals, including calcium, zinc, magnesium, iron, vitamins A and D, vitamins C and E, and vitamin B-6 [4,5]. The Academy of Nutrition and Dietetics (formerly the

\section{() Biomed Central}


American Dietetic Association) urges improvement in overall dietary habits as the primary tool for improving nutrient intake, but the organization's position paper on nutrient supplementation also recognizes that dietary supplements may have a role to play in helping people achieve nutritional goals [6]. The Dietary Reference Intakes established by the Institute of Medicine suggest supplemental intakes of some nutrients for some population groups, such as folic acid for women of childbearing age and vitamin B-12 for people over the age of 50, and the 2010 Dietary Guidelines for Americans also incorporate these recommendations $[7,8]$. The National Osteoporosis Foundation recognizes that some people may need supplemental intakes of calcium and vitamin $\mathrm{D}$ to reach levels considered to be necessary to build and maintain optimum bone mass during growth and early adulthood and to reduce bone loss during aging [9]. Researchers at the Harvard School of Public Health have designed a modified Food Guide Pyramid with a sidebar recommending a "daily multivitamin plus extra vitamin D (for most people)" [10]. Long chain omega-3 fatty acids such as EPA and DHA are consumed at very low levels by most Americans, and increases in intake could improve cardiovascular health and also provide other benefits [11]. Fiber intakes in the U.S. are also low, and fiber supplements as well as consuming more foods high in fiber could be beneficial for a large fraction of the population [12].

While the prevalence of consumer usage of dietary supplements is well documented, less attention has been paid to usage among health professionals and to whether health professionals recommend dietary supplements to their patients or clients. As part of a series of surveys on healthcare professionals' practices relating to dietary supplements, we conducted a survey to examine the extent to which dietitians use dietary supplements or recommend dietary supplements to their clients.

\section{Methods}

The Council for Responsible Nutrition (CRN), a trade association representing the dietary supplement industry, contracted with Ipsos Public Affairs to conduct a series of surveys of healthcare professionals regarding their use of dietary supplements and whether they recommended dietary supplements to their patients or clients. The three phases of the "Life...supplemented" Healthcare Professionals Impact Study (HCP Impact Study) included a 2007 survey of physicians and nurses; a 2008 survey of cardiologists, dermatologists and orthopedists; and this 2009 survey of dietitians, which also included surveys of nurse practitioners and pharmacists (data on nurse practitioners and pharmacists not included in this report). "Life...supplemented" is a consumer wellness initiative funded by a number of CRN member companies and by the CRN Foundation.

The survey of dietitians was administered online between October 3 and October 11, 2009, to 300 Registered Dietitians (RDs) who had an office-based practice in a clinic or in private practice and who reported seeing at least one patient per week at their practice site. The survey sample size was selected to provide $95 \%$ confidence that the sampling error would not exceed plus-or-minus $5.7 \%$, and recruitment was discontinued once the desired sample size had been reached. The 300 RDs consisted of 56 members of the eRewards U.S. online panel and another 244 from a database obtained from states' Registered Dietitian licensure records.

The eRewards panel is a U.S. online panel including over 1,500 dietitians who "opted into" the panel in order to take part in market research surveys in exchange for a points-based incentive. A total of 498 registered dietitians who are part of the eRewards panel were invited to take part in the survey, and 207 responded. The response rate of $42 \%$ was well within the norms for online surveys conducted among eRewards panel members from this profession. Among those who responded, 27\% met all qualifications and completed the entire survey. The remainder consisted of dietitians who did not meet all qualifications necessary to take part in the survey (57\%); met the desired qualifications, but failed to complete the entire questionnaire (4\%); or did not take part in the survey because the target number of completed interviews had been achieved (12\%). Qualified respondents included only those who described their primary occupation as Registered Dietitian and reported seeing clients weekly as part of their practice in an office or a clinic.

To complement the sample, an additional comprehensive database of dietitians originally sourced from states' Dietitians licensure records updated quarterly was also used. A total of 1,700 randomly selected, pre-qualified dietitians from that database were sent an invitation to take part in the survey. As compensation for their participation, they were offered an honorarium of \$15. A total of 671 dietitians responded. The response rate of $39 \%$ was typical of online surveys among dietitians sourced from this database. Among those who responded, 38\% met all qualifications and completed the entire survey, while $49 \%$ did not meet all the qualifications needed to take part in the survey, 9\% were excluded because the target number of completed interviews had been achieved, and 3\% met the desired qualifications, but failed to complete the entire questionnaire. Qualified respondents included only those who described their primary occupation as Registered Dietitian and reported seeing clients weekly as part of their practice in an office or a clinic. 
The letters inviting Registered Dietitians from both sample sources to take part in the survey did not identify the subject of the survey. To protect against conflicts of interest, dietitians were not considered eligible for the survey if they were affiliated with a pharmaceutical or dietary supplement company or a market research firm or advertising agency.

The dietitians were asked whether they were "regular" users of dietary supplements. The term "regular" was not defined, except in contrast to other options, which included "occasional" use (taking products throughout the year when they think of it or when the need arises) or "seasonal" use (taking them only during part of the year such as during the cold/flu season or allergy season). Dietitians who described themselves as regular users were asked whether they regularly used a variety of dietary supplements (vitamins, minerals, herbal products, sports nutrition or specialty supplements) or whether they regularly used typically only a multivitamin or multivitaminmineral. The terms "multivitamin" and "multivitaminmineral" were not defined in the survey instrument, as these are the accepted terms of commerce used to identify products containing all or most of the 13 vitamins, with or without one or more essential minerals. The dietitians were asked to identify the specific products they used (but not the level or dosage of each component) and to indicate their reasons for using dietary supplements. The respondents were also asked about the number of years they had been taking supplements and whether other members of their household took them.

Dietitians were also asked whether they "ever recommend dietary supplements" to clients, and if so, to specify their reasons for doing so. The reasons for personally using dietary supplements and for recommending supplements to clients were selected by respondents from a list of over 30 options provided in the questionnaire and described in more detail in the Results section of this report. For the most part, the list of options provided in the questionnaire for using supplements and for recommending supplements were the same, but a few (such as questions about men's health issues) appeared only on one list or the other. In addition to the provided options, participants could mention "other" reasons for using and recommending dietary supplements.

Respondents were asked what resources they trusted for reliable information for making decisions or recommendations about dietary supplements. Their attitudes about supplements and about health and wellness were also probed.

\section{Results}

The 300 dietitians who responded to this survey were almost all female (96\%), and $84 \%$ were in the age range
30 to 59 (27\% in their $30 \mathrm{~s}, 24 \%$ in their $40 \mathrm{~s}$, and $33 \%$ in their $50 \mathrm{~s}$ ). They were geographically dispersed, with $37 \%$ in the midwestern U.S., $31 \%$ in the south, $18 \%$ in the northeast, and $14 \%$ in the west. Forty-four percent of the respondents had been qualified as dietitians for more than 20 years, $28 \%$ for 11 to 20 years, $24 \%$ for 4 to 10 years, and only $4 \%$ for less than 4 years. Almost three-quarters (74\%) were members of the American Dietetic Association (now the Academy of Nutrition and Dietetics). Most of the dietitians surveyed (66\%) said they saw 1 to 50 clients per week in an office or clinic setting, but $34 \%$ saw a larger number. Table 1 summarizes demographic characteristics and overall patterns of supplement use reported by the dietitians surveyed.

Almost all of the dietitians surveyed (96\%) said they had used a dietary supplement (regularly, occasionally, or seasonally) during the previous year, as shown in

Table 1 Demographic characteristics and reported use of dietary supplements by all dietitians surveyed $(n=300)$

\begin{tabular}{|c|c|c|}
\hline Characteristic & Description & Percent \\
\hline \multirow[t]{2}{*}{ Gender } & Female & $96 \%$ \\
\hline & Male & $4 \%$ \\
\hline \multirow[t]{5}{*}{ Age } & Under 30 & $7 \%$ \\
\hline & 30 to 39 & $27 \%$ \\
\hline & 40 to 49 & $24 \%$ \\
\hline & 50 to 59 & $33 \%$ \\
\hline & 60 to 69 & $8 \%$ \\
\hline \multirow[t]{4}{*}{ Region } & Midwest & $37 \%$ \\
\hline & South & $31 \%$ \\
\hline & Northeast & $18 \%$ \\
\hline & West & $14 \%$ \\
\hline \multirow[t]{4}{*}{ Years qualified in profession } & 3 years or less & $4 \%$ \\
\hline & 4 to 10 years & $24 \%$ \\
\hline & 11 to 20 years & $28 \%$ \\
\hline & 21 years or more & $44 \%$ \\
\hline \multirow[t]{3}{*}{ Clients seen per week } & 1 to 50 & $66 \%$ \\
\hline & 51 to 100 & $21 \%$ \\
\hline & Over 100 & $13 \%$ \\
\hline \multirow[t]{6}{*}{ Use of dietary supplements } & Any current use & $96 \%$ \\
\hline & Regular use & $74 \%$ \\
\hline & Occasional use & $20 \%$ \\
\hline & Seasonal use & $2 \%$ \\
\hline & Used in the past & $3 \%$ \\
\hline & Never used & $1 \%$ \\
\hline \multirow[t]{5}{*}{ Duration of supplement use } & No current use & $4 \%$ \\
\hline & 3 years or less & $16 \%$ \\
\hline & 4 to 10 years & $41 \%$ \\
\hline & 11 to 20 years & $19 \%$ \\
\hline & Over 20 years & $19 \%$ \\
\hline
\end{tabular}


Table 1. There was no significant difference in the overall prevalence of supplement use according to age, region, or years qualified in practice (data not shown). Seventy-four percent of the dietitians in this survey indicated that they were regular users of dietary supplements. This included 36\% who said they regularly used a variety of supplements and $38 \%$ who said their regular use typically consisted only of a multivitamin or a multivitamin/mineral supplement. Twenty percent said they used supplements occasionally, and $2 \%$ said they used supplements seasonally. Three percent said they had used supplements in the past but no longer did so, and only $1 \%$ said they had never used dietary supplements. Seventy-two percent of the dietitians surveyed said that at least one other member of their household also used dietary supplements.

Among the dietitians who said they used dietary supplements at least some of the time, $43 \%$ had taken them for 4 to 10 years, $20 \%$ had taken them for 11 to 20 years, and $20 \%$ had taken them for over 20 years. Only $16 \%$ had taken them for 3 years or less. The top three reasons for taking dietary supplements were for bone health $(58 \%)$, for overall health and wellness benefits (53\%), and to fill nutrient gaps in the diet (42\%).

The prevalence of multivitamin use was high, with $84 \%$ of the dietitians saying they had taken a multivitamin within the past year, compared to $63 \%$ who had taken calcium, $47 \%$ who had taken omega-3 or fish oil supplements, $43 \%$ who had taken vitamin D, $29 \%$ who had taken vitamin C, $24 \%$ who had taken probiotics, $23 \%$ who had taken B vitamins, $22 \%$ who had taken fiber supplements, $18 \%$ who had taken green tea supplements, $13 \%$ who had taken flax seed oil, and $11 \%$ who had taken glucosamine and/or chondroitin. Table 2 shows the dietary supplements taken during the previous year by more than $10 \%$ of the dietitians surveyed.

Table 2 Dietary supplements used in the previous year (regularly, occasionally, or seasonally) by more than $10 \%$ of the dietitians surveyed

\begin{tabular}{ll}
\hline Dietary supplement & Percent using in previous year \\
\hline Multivitamin & $84 \%$ \\
\hline Calcium & $63 \%$ \\
\hline Omega 3/Fish oil & $47 \%$ \\
\hline Vitamin D & $43 \%$ \\
\hline Vitamin C & $29 \%$ \\
\hline Probiotics (e.g., acidophilus) & $24 \%$ \\
\hline Vitamin B or B complex & $23 \%$ \\
\hline Fiber & $22 \%$ \\
\hline Green tea & $18 \%$ \\
\hline Flax seed oil & $13 \%$ \\
\hline Glucosamine/chondroitin & $11 \%$ \\
\hline
\end{tabular}

When asked if they "ever recommend dietary supplements to clients," $97 \%$ of the dietitians surveyed said they did. There was no significant difference in the prevalence of recommending dietary supplements according to age, region, or years in practice (data not shown). The top seven reasons for recommending dietary supplements, cited by more than $40 \%$ of the respondents who recommend supplements to their clients, were bone health (70\%), filling nutrition gaps (67\%), overall health and wellness benefits (49\%), lowering cholesterol (46\%), heart health $(46 \%)$, dietary pattern/vegetarian/ vegan $(43 \%)$, and digestive or gastrointestinal health (39\%). Diabetes or glucose control was cited by $27 \%$ of dietitians and eating disorders were cited by $19 \%$ of dietitians as reasons for recommending supplements; these conditions were not included in the list of potential reasons for dietitians' personal use of dietary supplements. Table 3 shows the reasons common to both lists that were selected by at least $10 \%$ of survey respondents for personal use of dietary supplements or for recommending dietary supplements to clients. Reasons cited by 6 to $9 \%$ of the respondents included sleep problems, cognitive function, and anti-aging. Reasons cited by $5 \%$ or fewer included men's health issues (prostate health or sexual function), depression, stress relief, allergies, musculoskeletal pain, women's health (painful periods, PMS), insomnia, anxiety, headaches, and participation in a clinical trial.

The most trusted source of information for dietitians consisted of professional journals, cited by $80 \%$ of respondents. Three other trusted sources, each cited by more than $50 \%$ of the dietitians surveyed, included clinical studies in scientific journals (72\%), clinical guidelines from professional organizations (72\%), and continuing education conferences (71\%).

Eighty-seven percent of the respondents said their clients are "generally comfortable telling me about their dietary supplement usage." The same proportion (87\%) said they agreed with the statement, "There are gaps in clients' diets that could effectively be addressed with dietary supplements." However, only $23 \%$ of the dietitians in this survey believe that their clients have a good understanding of the appropriate daily intake for dietary supplements.

While only $5 \%$ of the dietitians surveyed said they personally used dietary supplements for reasons related to sports performance, $14 \%$ of them said they sometimes recommended supplements for sports-related reasons, and $46 \%$ expressed an interest in continuing education on this topic.

The dietitians surveyed had a very high level of adoption of healthy habits, including trying to eat a balanced diet (96\%), managing stress (92\%), visiting their own healthcare professional regularly $(86 \%)$, exercising 
Table 3 Reasons for recommending and using dietary supplements, selected by $10 \%$ or more of dietitians surveyed, from a provided list of reasons

\begin{tabular}{|c|c|c|}
\hline List of reasons (Provided to survey respondents) & Reason for recommending $(n=300)$ & Reason for using $(\mathrm{n}=287)$ \\
\hline Bone health & $70 \%$ & $58 \% *$ \\
\hline Fill nutrition gaps & $67 \%$ & $42 \%{ }^{*}$ \\
\hline Overall health/wellness benefits & $49 \%$ & $53 \%$ \\
\hline Lower cholesterol & $46 \%$ & $16 \% *$ \\
\hline Heart health & $46 \%$ & $25 \% *$ \\
\hline Dietary pattern (vegetarian/vegan) & $43 \%$ & $5 \% *$ \\
\hline Digestive/gastrointestinal health & $39 \%$ & $26 \% *^{*}$ \\
\hline Maintain healthy cholesterol & $33 \%$ & $17 \% *$ \\
\hline Women's health (prenatal, pregnancy) & $29 \%$ & $12 \% *$ \\
\hline Immune health & $25 \%$ & $25 \%$ \\
\hline Joint health & $22 \%$ & $15 \% *$ \\
\hline Weight management & $17 \%$ & $6 \% *$ \\
\hline Women's health (menopause) & $15 \%$ & $10 \%$ \\
\hline Skin, hair and nails & $15 \%$ & $13 \%$ \\
\hline Flu/colds & $15 \%$ & $21 \%$ \\
\hline Women's health (other) & $14 \%$ & $14 \%$ \\
\hline Sports nutrition and performance & $14 \%$ & $5 \% *$ \\
\hline Eye health & $13 \%$ & $9 \%$ \\
\hline Energy & $12 \%$ & $15 \%$ \\
\hline Energy balance & $10 \%$ & $6 \%$ \\
\hline Other & $10 \%$ & $5 \% *$ \\
\hline
\end{tabular}

regularly (83\%), maintaining a healthy weight $(80 \%)$ and regularly getting a good night's sleep (72\%). Only $24 \%$ said they often consumed large quantities of caffeine, and very few smoked (3\%) or consumed large quantities of alcohol (3\%).

Nearly all respondents (95\%) expressed an interest in continuing education (CE) about dietary supplements on a variety of topics. The specific subjects mentioned by more than $40 \%$ of the dietitians interested in CE about dietary supplements included: interactions of drugs and dietary supplements (74\%), basics about dietary supplements $(72 \%)$, how to counsel clients about dietary supplements $(70 \%)$, weight management $(68 \%)$, women's health $(65 \%)$, heart health $(65 \%)$, drug induced nutrient depletion (56\%), dietary supplement regulation (54\%), and sports nutrition supplements (48\%).

\section{Discussion}

Dietitians are uniquely qualified to evaluate the adequacy of nutrient intake and to make rational choices about dietary supplement use for themselves and for their clients or patients, when appropriate. While authoritative groups consistently encourage a "food first" approach to achieving nutrient adequacy, it is also recognized that most people have dietary intakes that fall short in some respects and that dietary supplements can make a contribution toward achieving nutritional goals [4-12].

The prevalence of regular dietary supplement use among dietitians (74\%) is comparable to that reported in some surveys of the general public and of health professionals. In NHANES 2003-2006, the overall prevalence of dietary supplement use in adults was $54 \%$, but it was $55 \%$ in women $31-50$ and $72 \%$ in women $51-70$ [2]. Since the query in NHANES relates to supplement use within the previous month, it captures mostly regular users, so the appropriate comparison within our survey is with regular users. In a large multiethnic cohort in the general population, $58 \%$ of men and $72 \%$ of women said they used one of eight dietary supplements regularly, defined as at least once a week [13]. Two surveys of health professionals enrolled in an online course on dietary supplements reported levels of usage in excess of $80 \%[14,15]$. In the "Life...supplemented" HCP Health Impact Studies conducted in 2007, 2008, and 2009, regular dietary supplement use was reported for over $70 \%$ of dietitians and nurse practitioners; around $60 \%$ of pharmacists, nurses and dermatologists; about 
$50 \%$ of family care physicians, ob/gyn physicians, and orthopedists; and $37 \%$ of cardiologists $[16,17]$.

It is notable that $96 \%$ of the dietitians we surveyed reported using dietary supplements at least occasionally or seasonally if not regularly, and $97 \%$ said they "ever recommended" dietary supplements to clients. Our survey is not representative of all dietitians, as it focuses only on a particular segment of dietitians, namely those who see clients in their office or clinic on a regular basis. Presumably the clients come with questions or issues to be addressed, and dietitians engaged in counseling such clients may be more likely than dietitians in other practice settings to recommend specific actions, including the use of dietary supplements.

The top three reasons for using and recommending dietary supplements were the same in this sample of dietitians: bone health, filling nutrition gaps, and overall health/wellness benefits. All three of these issues are relevant to dietitians as well as to their clients. Bone health was cited by $58 \%$ as a reason for personal use and by $70 \%$ as a reason for recommending dietary supplements to clients. Calcium and vitamin D supplementation are recognized as appropriate for bone health, for people who do not consume adequate amounts of these nutrients from food, and counseling by dietitians has been shown to improve compliance with calcium recommendations by women with low bone density $[9,18]$.

Overall health and wellness was reported to be the reason for using dietary supplements by $53 \%$ and the reason for recommending dietary supplements by about the same proportion (49\%). Filling nutrient gaps in the diet was the reason given for personal use by $42 \%$, but was cited by $67 \%$ as the reason for recommending dietary supplements, likely reflecting the fact that clients may be less knowledgeable than dietitians about planning for adequate dietary intakes. Other reasons cited by more than $40 \%$ of respondents for recommending supplements included purposes related to helping protect against disease, including lowering cholesterol (46\%) and supporting heart health (46\%), although the dietitians were less likely to personally use dietary supplements for these reasons.

Dietary pattern (vegetarian or vegan) was cited by $43 \%$ of dietitians in this survey as a reason for recommending dietary supplements but by only $5 \%$ as a reason for personal supplement use. The prevalence of this issue as a basis for recommendations to clients is probably related to the fact that there are recognized potentials for nutrient shortfalls in such diets, and vegetarians and vegans are often advised to seek the counsel of a dietitian to ensure against inadequate intakes of nutrients such as vitamin B-12 [19]. Women's health (prenatal, pregnancy) was cited by $29 \%$ of dietitians as a reason for recommending dietary supplements, but by only $12 \%$ as a reason for personal use of supplements, likely reflecting differences in age between the dietitians and some of their clients. Almost 2/3 of the dietitians surveyed (65\%) were age 40 or older. Health care providers generally recommend a prenatal multivitamin supplement during pregnancy, and $\mathrm{CDC}$ recommends a multivitamin with folic acid for women of childbearing age to reduce the risk of having a baby with a neural tube birth defect [20].

Some of the dietitians in this survey (14\%) indicated that they sometimes recommended dietary supplements to clients for reasons related to sports nutrition, though only $5 \%$ selected sports nutrition and performance as a reason for personal supplement use. There are published recommendations available to guide dietitians in advising clients on issues relating to sports nutrition [21,22]. The U.S. and Canadian dietetic associations, jointly with the American College of Sports Medicine, have issued a position statement noting that optimal nutrition can enhance sports performance as well as recovery from exercise and have evaluated the potential role of some supplements as well as dietary habits [22].

Dietitians can help their clients evaluate nutritional needs and select rational dietary supplements. Recognizing that there are quality issues with some products, dietitians could direct clients toward companies with a reputation for quality or toward products bearing a quality seal.

\section{Conclusions}

Dietitians, like other health professionals, use dietary supplements themselves and also recommend dietary supplements to their patients or clients. The top three reasons for personally using dietary supplements and for recommending them to clients were the same and included bone health, overall health and wellness, and filling nutrient gaps in the diet. Some other reasons were more commonly cited as the basis for recommending dietary supplements, rather than reasons for personal use, likely due to the differing conditions and needs of clients. These included reasons relating to special diets, pregnancy, and sports nutrition.

\section{Abbreviations}

CRN: Council for Responsible Nutrition; HCP Impact Study: "Life... supplemented" Healthcare Professionals Impact Study; NHANES: National Health and Nutrition Examination Survey; RDs: Registered Dietitians.

\section{Acknowledgements}

The Council for Responsible Nutrition and the CRN Foundation provided funding for the survey and for AD's consulting services related to preparation and submission of the manuscript.

\section{Author details}

'Dickinson Consulting, LLC, 3432 Denmark Avenue, \#350, St. Paul, MN 55123, USA. ${ }^{2}$ Sports Nutrition, UPMC Center for Sports Medicine, University of 
Pittsburgh Medical Center, 3200 S. Water Street, Pittsburgh, PA 15203, USA ${ }^{3}$ Ipsos Public Affairs, 1700 Broadway, New York, NY 10019, USA

\section{Authors' contributions}

$A D$ prepared the original draft of the article, for subsequent evaluation and elaboration by all of the authors working collaboratively. NB and JF participated in the design and administration of the survey, including the data analysis. All of the authors provided meaningful insight regarding the results and implications of the survey findings, in the context of previously reported research, and all approved the final version of the article.

\section{Competing interests}

AD is a consultant to the Council for Responsible Nutrition (CRN) and was formerly a VP and President of the association. LB has consulted with CRN regarding the "Life...supplemented" wellness program. NB is SVP and JF is Senior Research Manager for Ipsos Public Affairs, which conducted the survey for CRN.

Received: 28 October 2011 Accepted: 14 March 2012

Published: 14 March 2012

\section{References}

1. Radimer K, Bindewald B, Hughes J, Ervin B, Swanson C, Picciano MF: Dietary supplement use by US adults: data from the National Health and Nutrition Examination Survey, 1999-2000. Am J Epidemiol 2004, 160(4):339-349.

2. Bailey RL, Gahche JJ, Lentino CV, Dwyer JT, Engel JS, Thomas PR, Betz JM, Sempos CT, Picciano MF: Dietary supplement use in the United States, 2003-2006. J Nutr 2011, 141(2):261-266.

3. Dwyer J: Why do Americans use dietary supplements? Presentation at American Dietetic Association Food \& Nutrition Conference and Expo (FNCE), October 24, 2005, St. Louis, Missouri , (Accessed July 2011 at: http://ods.od. nih.gov/pubs/fnce2005/J-Dwyer-Why\%20Do\%20Americans\%20Use\% 20Dietary\%20Supplements.pdf.).

4. Moshfegh A, Goldman J, Cleveland L: What we eat in America, NHANES 2001-2002: Usual nutrient intakes from food compared to Dietary Reference Intakes. U.S. Department of Agriculture. Agriculture Research Service; 2005.

5. Moshfegh A, Goldman J, Ahuja J, Rhodes D, LaComb R: What we eat in America, NHANES 2005-2006; Usual nutrient intakes from food and water compared to 1997 Dietary Reference Intakes for vitamin D, calcium, phosphorus, and magnesium. U.S. Department of Agriculture. Agriculture Research Service; 2009.

6. Marra MV, Boyar AP: Position of the American Dietetic Association: nutrient supplementation. J Am Diet Assoc 2009, 109(12):2073-2085.

7. Institute of Medicine: Dietary Reference Intakes: The Essential Guide to Nutrient Requirement. Washington, D.C.: National Academies Press; 2006.

8. Department of Agriculture and Department of Health and Human Services: Dietary Guidelines for Americans, Seventh Edition. Washington, D.C. Government Printing Office; 2010.

9. National Osteoporosis Foundation: Calcium: What you should know., (Accessed July 2011 at: http://www.nof.org.)

10. Harvard School of Public Health: The Nutrition Source: Healthy eating plate and healthy eating pyramid. [http://www.hsph.harvard.edu/ nutritionsource/what-should-you-eat/pyramid/], (accessed December 16, 2011).

11. Harris WS, Mozaffarian D, Lefevre M, Toner CD, Colombo J, Cunnane SC, Holden JM, Klurfeld DM, Morris MC, Whelan J: Towards establishing dietary reference intakes for eicosapentaenoic and docosahexaenoic acids. J Nutr 2009, 139(4):804S-819S.

12. Slavin JL: Position of the American Dietetic Association: health implications of dietary fiber. J Am Diet Assoc 2008, 108(10):1716-1731.

13. Foote JA, Murphy SP, Wilkens LR, Hankin JH, Henderson BE, Kolonel LN: Factors associated with dietary supplement use among healthy adults of five ethnicities: the Multiethnic Cohort Study. Am J Epidemiol 2003, 157(10):888-897.

14. Gardiner P, Woods C, Kemper KJ: Dietary supplement use among health care professionals enrolled in an online curriculum on herbs and dietary supplements. BMC Complement Altern Med 2006, 6:21.
15. Kemper KJ, Gardiner P, Woods C: Changes in use of herbs and dietary supplements (HDS) among clinicians enrolled in an online curriculum. BMC Complement Altern Med 2007, 7:21.

16. Dickinson A, Boyon N, Shao A: Physicians and nurses use and recommend dietary supplements: report of a survey. Nutr J 2009, 8:29.

17. Dickinson A, Shao A, Boyon N, Franco JC: Use of dietary supplements by cardiologists, dermatologists and orthopedists: report of a survey. Nutr J 2011, 10:20.

18. French $M R$, et al: A prospective study to identify factors affecting adherence to recommended daily calcium intake in women with low bone mineral density. J Am Coll Nutr 2008, 27:88-95.

19. Craig WJ, Mangels AR: Position of the American Dietetic Association: Vegetarian Diets. J Am Diet Assn 2009, 109:1266-1282.

20. Picciano MF, McGuire MK: Use of dietary supplements by pregnant and lactating women in North America. Am J Clin Nutr 2009, 89:663S-667S.

21. Bonci L: Supplements: Help, harm, or hype? How to approach athletes. Current Sports Medicine Reports 2009, 4:200.

22. Rodriguez NR, DiMarco MN, Langley S: Position of the American Dietetic Association, Dietitians of Canada, and the American College of Sports Medicine: Nutrition and Athletic Performance. J Am Diet Assn 2009, 109:509.

doi:10.1186/1475-2891-11-14

Cite this article as: Dickinson et al:: Dietitians use and recommend dietary supplements: report of a survey. Nutrition Journal 2012 11:14.

\section{Submit your next manuscript to BioMed Central and take full advantage of:}

- Convenient online submission

- Thorough peer review

- No space constraints or color figure charges

- Immediate publication on acceptance

- Inclusion in PubMed, CAS, Scopus and Google Scholar

- Research which is freely available for redistribution

Submit your manuscript at www.biomedcentral.com/submit
C Biomed Central 